\title{
Absorption of glucose and galactose and digestion and absorption of lactose by the preruminant calf
}

\author{
By N. B. COOMBE* aNd R. H. SMITH \\ National Institute for Research in Dairying, Shinfield, \\ Reading $R G 2,9 A T$
}

(Received 3 November 1972-Accepted 16 February 1973)

1. Uptakes of glucose, galactose, glucose + galactose and lactose from the intestine were studied in preruminant calves fitted with cannulas in the proximal small intestine, and in slaughtered calves. Responses in concentration of blood sugar to the presence of sugar in the small intestine were also investigated.

2. Glucose and galactose were absorbed at about the same rate when present in the intestine separately. The rate for each sugar approached a maximum with increasing sugar concentration in the lumen.

3. When glucose and galactose were present in the intestine together, the rate of galactose absorption was greatly depressed; that of glucose was virtually unaffected. Consequently, when calves were fed with mixtures of glucose and galactose, absorption of galactose in the proximal intestine, where the relative concentration of glucose was high, was depressed. In the more distal intestine where the glucose concentration had fallen, absorption of galactose was rapid. Both sugars were absorbed efficiently during their passage through the whole small intestine, but at different sites.

4. Galactose appeared in the blood after galactose alone was given but conversion of some galactose into glucose always occurred. Results of experiments in which $\left[{ }^{14} \mathrm{C}\right]$ galactose, together with glucose, was infused into the duodenum of a calf suggested that under these conditions the rate of galactose absorption was depressed to such an extent that nearly all the galactose entering the blood was converted into glucose.

5. Lactose hydrolysis occurred much more rapidly than the absorption of its constituent monosaccharides. Thus, after lactose was fed to the calves, glucose and galactose accumulated in the lumen of the proximal small intestine. A similar accumulation occurred when lactose was infused into loops of small intestine. The rate-limiting step in the total absorption of lactose in the young calf was not, therefore, the hydrolysis stage, as reported for other mammals. The absorption of the released glucose and galactose occurred in a manner similar to that described above for mixtures of glucose and galactose.

The preruminant calf differs from most other mammals in several aspects of its ability to utilize dietary carbohydrates. For example, it is unable to utilize dietary sucrose (Siddons, Smith, Henschel, Hill \& Porter, I969), apparently because of a complete lack of intestinal sucrase activity (Siddons, I968), and it appears to absorb fructose poorly or not at all (Velu, Kendall \& Gardner, r960). The young calf is, nevertheless, well able to use lactose, and it efficiently absorbs glucose and galactose when these sugars are present in the intestine scparately; galactose given alone leads to the appearance of considerable amounts of galactose in the blood (Velu et al. 1960; Siddons et al. I969). In calves given diets containing glucose + galactose or lactose, however, Siddons et al. (I969) found that the increase in concentration of total reducing sugar in the blood could be accounted for almost completely by an increase in the concentration of blood glucose. These results could suggest that glucose is

* Present address: Geriatric Medicine, Southampton General Hospital, Temona Road, Southampton SO9 $4 \mathrm{XY}$. 
absorbed preferentially to galactose under these conditions, but many factors, other than processes of absorption, may influence blood-sugar responses. The interrelationships between the mechanism of lactose digestion and glucose and galactose absorption in the calf remain poorly understood. In the present work these processes have been examined by studying the disappearance of sugars from the small intestine of the preruminant calf as well as their appearance in the blood. A short account of part of this work has been published earlier (Coombe \& Smith, 1971).

\section{EXPERIMENTAL}

\section{Animals and feeding}

Castrated Friesian bull calves, aged between 4 and 20 weeks, were used in all experiments with cannulated animals. In all other experiments, Guernsey bull calves, aged between $I$ and 8 weeks, were used.

All calves were reared on whole-milk diets given in amounts sufficient to maintain a body-weight gain of $0.25 \mathrm{~kg} / \mathrm{d}$ (Roy, Shillam, Hawkins \& Lang, I958). The milk given to calves over 3 weeks of age was supplemented with iron, manganese, copper and magnesium, and vitamins $\mathrm{A}, \mathrm{E}$ and cholecalciferol. Each feed of synthetic milk (subsequently referred to as diet $\mathrm{S}$ ) used in some experiments was prepared as follows. The carbohydrate under investigation was dissolved in $\mathrm{I} \cdot 6 \mathrm{~kg}$ water to which $34 \mathrm{ml}$ of a sodium citrate solution (solution $\mathrm{A}$, see below) had been added. Calcium caseinate $(89 \mathrm{~g})$ was then dispersed in this solution and $29 \mathrm{~g}$ margarine plus $\mathrm{I} \cdot 4 \mathrm{~g}$ Lubrol W (Imperial Chemical Industries Ltd, Blackley, Manchester) (warmed until liquid in $125 \mathrm{ml}$ water) were added. Mineral solutions were prepared as follows: solution A contained $22 \mathrm{~g} \mathrm{NaOH}$ and $20 \mathrm{~g}$ citric acid in I l; solution $\mathrm{B}$, II $\mathrm{g} \mathrm{Na}_{2} \mathrm{HPO}_{4}, 70 \mathrm{~g}$ $\mathrm{K}_{2} \mathrm{HPO}_{4}$ and $\mathrm{I}_{5} \mathrm{~g} \mathrm{KH}_{2} \mathrm{PO}_{4}$ in $\mathrm{I} \mathrm{l}$; solution $\mathrm{C}$, $142 \mathrm{~g} \mathrm{CaCl}_{2} .6 \mathrm{H}_{2} \mathrm{O}$ and $50 \mathrm{~g}$ $\mathrm{MgCl}_{2} \cdot 6 \mathrm{H}_{2} \mathrm{O}$ in I 1. Portions of solution A (5I ml), solution B $(85 \mathrm{ml})$ and solution C (4I $\mathrm{mI}$ ) were mixed and added to the feed, and the whole mixture was homogenized for $5 \mathrm{~min}$ in a Silverson homogenizer (Model AX; Silverson Machines, London SEI).

\section{Analytical methods}

Carbohydrates. Samples of digesta and whole blood were diluted ( $\mathrm{ml}$ sample with $3 \mathrm{ml}$ water) and deproteinized by the addition of $0.5 \mathrm{ml}$ each of solutions of $0.15 \mathrm{M}-$ barium hydroxide and zinc sulphate $(5 \circ \mathrm{g} / 1)$. The glucose content of digesta samples was measured manually by the tris-glucose oxidase method (Dahlqvist, r96x). The automated method used for glucose estimation in blood samples was that described in the bulletin issued by C. F. Boehringer \& Soehne (Mannheim, Germany), with their Biochemical Test Combination TBAP ${ }_{5} 5756$. In all samples containing galactose alone, galactose was estimated from the total reducing-sugar content as measured by the copper-neocuproine method (bulletin supplied by Technicon Instruments Company Ltd, Basingstoke, Hants). In mixtures of glucose and galactose, galactose was estimated as the difference between the total reducing sugar and glucose contents. The values for galactose obtained in this way were corrected to allow for the fact that galactose was only about $70 \%$ as sensitive to the reducing-sugar method as glucose. 
In some samples, a specific method using galactose oxidase was also used (Roth, Segal \& Bertoli, I965). Complex mixtures of sugars were analysed by ion-exchange chromatography of their borate complexes (Smith \& McAllan, I97I).

Polyethylene glycol-turbidometric method. Polyethylene glycol (PEG) in digesta samples was measured by a modification by Smith (1958) of the method of Hydén (1955).

${ }^{14}$ C-labelled PEG in digesta samples. Digesta samples were homogenized for $5 \mathrm{~min}$ at top speed in an Ato-Mix blender (Measuring \& Scientific Equipment Ltd, London). After centrifugation for $45 \mathrm{~min}$ at $1000 \mathrm{~g}$ the supernatant fraction was decanted off; I $\mathrm{ml}$ was taken and shaken with $\mathrm{I} \mathrm{ml}$ of $\mathrm{M}$-hyamine hydroxide in methanol (Nuclear Enterprises Ltd, Edinburgh). This was mixed with Io $\mathrm{ml}$ phosphor reagent $(0.3 \mathrm{~g}$ I,4-bis(5-phenyl-2-oxazolyl)-benzene, $4 \mathrm{~g}$ diphenyl oxazole, $80 \mathrm{~g}$ naphthalene, $430 \mathrm{ml}$ distilled anisole, $560 \mathrm{ml}$ distilled methyl-oxyethanol). Concentrated $\mathrm{HCl}(0 . \mathrm{I} \mathrm{ml})$ was then added. Radioactivity was measured by liquid $\beta$-scintillation counting in a Packard Tri-Carb Liquid Scintillation Spectrophotometer, Model $3003 \cdot{ }^{14} \mathrm{C}$-labelled toluene was used as an internal standard checked against $n$-hexadecane- ${ }^{-14} \mathrm{C}$ reference material (supplied by the Radiochemical Centre, Amersham, Bucks.).

${ }^{14}$ C-labelled galactose in plasma samples. Plasma $(0.5 \mathrm{ml})$ was digested with $\mathrm{I} \mathrm{ml}$ M-hyamine hydroxide in methanol by shaking for $9 \circ$ min at $55^{\circ}$. Phosphor reagent (as above) was then added and the same procedure followed as for $\left[{ }^{14} \mathrm{C}\right] \mathrm{PEG}$.

\section{Intestinal loop experiments}

\section{Animal experiments}

Three calves ( $\mathrm{A}$ A, $2 \mathrm{~A}$ and $3 \mathrm{~A}$ ) were each fitted at 2 weeks of age with two sets of re-entrant cannulas. The cannulas used were prepared from a flexible plastic as described by Ash (1962). The proximal pair of cannulas was positioned just below the entrance of the bile duct into the duodenum. The distal pair of cannulas was positioned approximately $200-400 \mathrm{~cm}$ further along the intestine; their exact position could only be determined after slaughter. When an animal was not being used for an experiment, digesta flowed through the loop of intestine situated between the pairs of cannulas. During an experimental period, the efferent cannula of the proximal pair was connected to the afferent cannula of the distal pair, thus isolating the loop of intestine yet allowing digesta to flow through the rest of the intestine.

In any one experiment, a number of solutions of a single sugar or sugar mixture at different concentrations (made isotonic to blood with $\mathrm{Na}_{2} \mathrm{SO}_{4}$ ) plus ${ }^{14} \mathrm{C}$-labelled PEG were infused successively into the proximal end of the loop at a rate of $500 \mathrm{ml} / \mathrm{h}$. This has been shown by Siddons et al. (1969) to be approximately the rate of passage of digesta into the duodenum during the first $3 \mathrm{~h}$ after feeding calves with whole-milk diets. Each sugar solution of a particular concentration was infused for $45 \mathrm{~min}$ and the effluent was collected for the last $\mathrm{I}_{5} \mathrm{~min}$ of this period. Preliminary experiments had shown that a steady state was achieved in this time. The rate of absorption of the sugar from the loop was calculated from the change in the sugar to PEG ratio. Experiments with the same sugar were repeated at least twice on different days. The monosaccharide concentrations used in a first experiment were infused in the order 
of $\mathrm{I} 8 \cdot 0,50 \cdot 4,39 \cdot 6,28 \cdot 8,7 \cdot 2, \mathrm{I} \cdot 8$ and $\mathrm{I} 8 \cdot 0 \mathrm{~g} / 1$; the $\mathrm{I} 8 \cdot 0 \mathrm{~g} / 1$ solution was always infused twice, once at the beginning and once at the end of each experiment to check that the absorptive properties of the loop did not change appreciably during the course of each experiment. There was never any appreciable difference between the two values; this is illustrated by the results shown in Fig. I. In alternate subsequent experiments the order of infusion indicated above was reversed as a check on 'carry-over' effects; no consistent or appreciable effects were apparent. The lactose concentrations used in all experiments were twice those given above for the monosaccharides.

\section{Slaughter experiments}

Six calves ( I B-6B) at I week of age and six calves $(7 \mathrm{~B}-12 \mathrm{~B})$ at 8 weeks of age were given a morning feed of the synthetic diet $\mathrm{S}$. In different experiments 100 g galactose, $100 \mathrm{~g}$ glucose $+100 \mathrm{~g}$ galactose or $200 \mathrm{~g}$ lactose were added to the diet together with $5 \mathrm{~g}$ PEG. Three hours after feeding (by which time, the feed residues had arrived at the terminal ileum), the calves were slaughtered by an intravenous injection of an overdose of veterinary Nembutal (Abbot Laboratories Ltd, Queenborough, Kent). This method of slaughter was chosen to minimize the disruption of the intestinal mucosa (Badawy, Campbell, Cuthbertson, Fell \& Mackie, r958). The abomasums and small intestines were exposed, clamped off at as many places as possible to restrict the movement of digesta, and removed. Each small intestine was divided into eight equal lengths and the contents of each section and of the abomasum were collected separately. The contents were then analysed for residual sugar and PEG.

\section{Blood sugar experiments}

Feeding experiments. Four calves ( $\mathrm{C}-4 \mathrm{C}$ ), aged $5^{-32} \mathrm{~d}$, were given a normal feed of whole milk at 17.00 hours on the day preceding the experiment. After an overnight fast they were given feeds of the synthetic diet $S$ plus various sugars. Samples of blood were taken through a I $50 \mathrm{~mm}$ nylon cannula (Portex nylon tubing - size $3 \mathrm{~V}$, i.d. $\mathrm{x} \cdot \mathrm{mm}$; Portex Ltd, Hythe, Kent) inserted into the jugular vein at least $30 \mathrm{~min}$ before feeding. Blood samples were taken immediately before feeding and at 0.5 , $\mathrm{I}, \mathrm{I} \cdot 5,2,3,4,5$ and $6 \mathrm{~h}$ after feeding. The samples were immediately deproteinized.

Duodenal infusion experiment. One calf $\left(5_{5} \mathrm{C}\right)$, aged $5^{-1} 3$ weeks, was given the synthetic diet $\mathrm{S}$ without any added sugar after an overnight fast. Solutions of glucose $(7 \circ \mathrm{g} / \mathrm{l})$, galactose $(7 \circ \mathrm{g} / 1)$ labelled with $\left[\mathrm{U}-{ }^{14} \mathrm{C}\right]$ galactose or glucose + galactose ( $7 \circ \mathrm{g} / 1$ of each sugar), the galactose again labelled with $\left[\mathrm{U}-{ }^{14} \mathrm{C}\right]$, were infused into a simple T-piece cannula in the proximal duodenum at a rate of $3 \mathrm{ml} / \mathrm{h}$ per $\mathrm{kg}$ bodyweight. Infusion began $\mathrm{r} h$ after feeding and continued for $2 \mathrm{~h}$. Blood samples (ro ml) were taken through a jugular cannula into heparinized tubes at intervals of $30 \mathrm{~min}$ during the $8 \mathrm{~h}$ after the infusion started.

Fugular infusion experiment. Three calves $(6 \mathrm{C}-8 \mathrm{C})$, aged $4^{-8}$ weeks, were each provided with nylon cannulas inserted into both jugular veins. Into one cannula, sugar solutions (made isotonic to blood with $\mathrm{NaCl}$ ) were infused at a rate of 


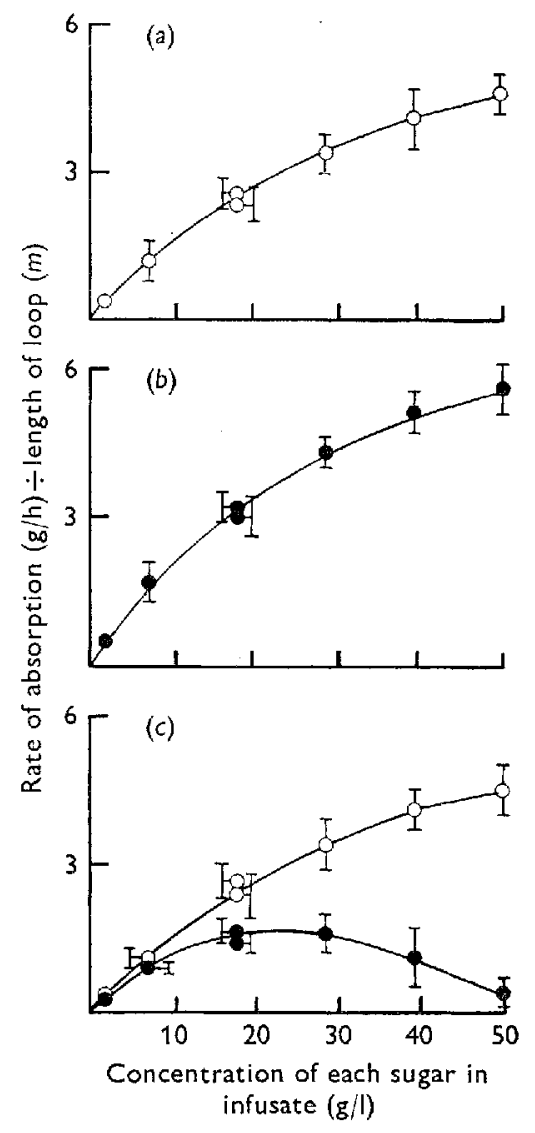

Fig. r. Rates of absorption of glucose $(O)$ and galactose (O) when solutions of $(a)$ glucose, (b) galactose and (c) equimolar mixtures of glucose and galactose, at different concentrations were infused at a rate of $500 \mathrm{ml} / \mathrm{h}$ into an isolated loop of intestine ( $1.9 \mathrm{~m}$ long) in calf $\mathrm{I}$ A. The proximal cannula of the loop was sited about $50 \mathrm{~mm}$ below the entrance of the bile duct into the duodenum. Results are the means (standard errors shown by the vertical bars) of values from three experiments.

$500 \mathrm{ml} / \mathrm{h}$ for $2 \mathrm{~h}$. Blood samples were taken from the other cannula before the infusion started and at intervals of 30 min during the $3 \mathrm{~h}$ after the infusion started.

\section{RESULTS}

\section{Uptake of sugars from the alimentary tract}

The results given in Fig. I $a, b$ show that, when glucose and galactose were infused separately into intestinal loops, their rates of removal per unit of sugar infused decreased with increasing concentrations of sugar in the infusate. The results suggest that absorption of both sugars involved a process which could be saturated, although a maximum rate of absorption was not achieved under our experimental conditions. The rates of absorption of galactose appeared to be slightly greater than the corresponding rates for glucose at each concentration of infusate. When these two sugars were infused in equimolar mixtures, however, the rate of galactose removal was 


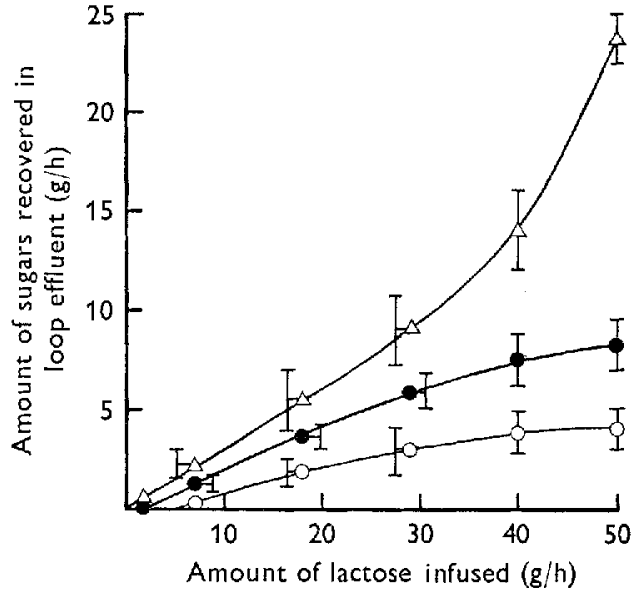

Fig. 2

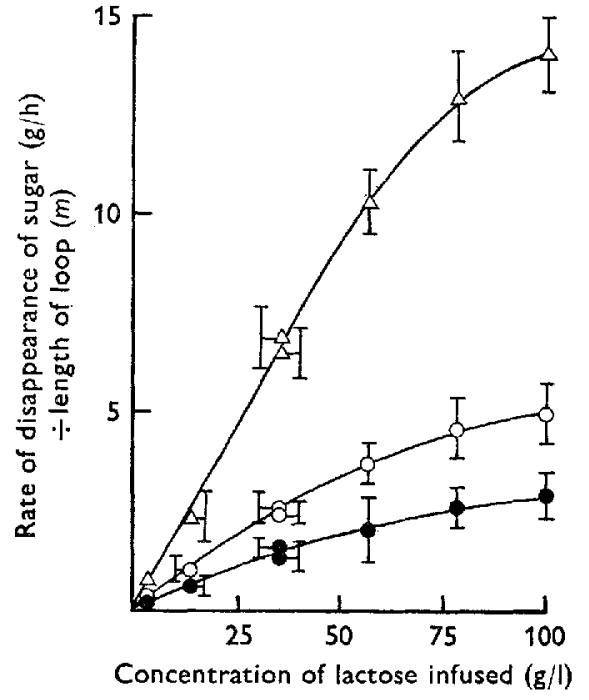

Fig. 3

Fig. 2. Recovery of glucose $(O)$, galactose $(\Theta)$ and lactose $(\triangle)$ in the effiuent from an isolated loop of intestine (sited as described in Fig. I) in calf I A into which different concentrations of lactose were infused at $500 \mathrm{ml} / \mathrm{h}$. Results are the means (standard errors shown by the vertical bars) of values from three experiments.

Fig. 3. Rate of disappearance of lactose $(\triangle)$ and rates of absorption of glucose $(O)$ and galactose (e) when solutions of different concentrations of lactose were infused at a rate of $500 \mathrm{ml} / \mathrm{h}$ into an isolated loop of intestine (sited as described in. Fig. I) in calf I A. Results are the means (standard errors shown by the vertical bars) of values from three experiments.

severely depressed, particularly at the higher concentrations of infusate used, but the rate of glucose uptake appeared to be virtually unaffected (Fig. I $c$ ).

The rates of absorption in Fig. I are expressed as the amounts of sugar removed in unit time divided by the length (in $\mathrm{m}$ ) of the gut loop. Since the rate of absorption of a sugar depends on its concentration in the gut lumen, the value derived in this way depends on the length of the loop used in the experiment. The range of loops used in our experiments $(\mathrm{I} \cdot 9-3.7 \mathrm{~m})$ was not, however, sufficiently great to cause much variation, and the values obtained for the different calves were always in close agreement.

Fig. 2 shows the amounts of lactose, glucose and galactose in the loop effluent after different amounts of lactose had been infused. The amount of lactose in the effluent increased in a non-linear manner as the amount of lactose infused increased, suggesting that the disappearance of lactose occurred by a process, presumably its hydrolysis, which tended to become saturated at high infusate concentrations, although full saturation was not attained.

Considerable amounts of glucose and even greater amounts of galactose were recovered in the loop effluent after infusion of lactose solutions. This did not appear to be due to lactase activity in sloughed-off mucosal cells, since incubation (at $37^{\circ}$ for $\mathrm{I} \mathrm{h}$ ) of duplicate $2 \mathrm{ml}$ samples of the loop effluent taken after infusion of each of the different concentrations of lactose did not lead to liberation of monosaccharides. 


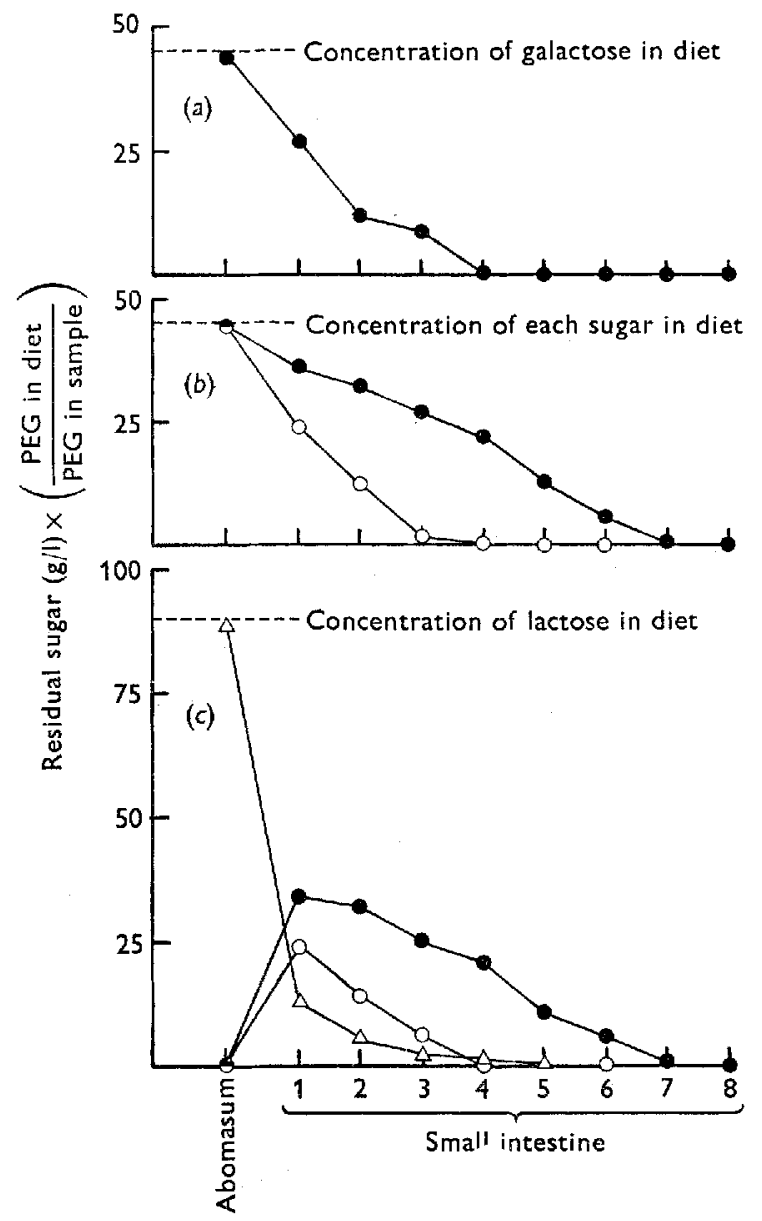

Fig. 4. Amounts, relative to polyethylene glycol (PEG), of glucose (O), galactose (e) and lactose $(\Delta)$ remaining in the abomasums and sections of the small intestines of $\mathrm{I}$-week-old calves slaughtered $3 \mathrm{~h}$ after they had been given feeds containing (a) roo $\mathrm{g}$ galactose, (b) roo g glucose + roo g galactose, and (c) $200 \mathrm{~g}$ lactose. The small intestines were divided into eight equal sections as described on p. 334 .

The net rates of absorption of the glucose and galactose released by hydrolysis of lactose are shown in Fig. 3. These values were obtained by calculating the amounts of monosaccharides removed in the loop and subtracting the amounts of monosaccharides recovered in the effluent. The rate of glucose absorption was considerably greater than that of galactose at all concentrations of lactose infusate. All the foregoing results for lactose absorption are for one calf. Similar relationships were demonstrated in two other calves which were examined similarly.

Samples of the loop effluent taken after infusion of lactose solutions were treated with borate and analysed for sugars by anion-exchange chromatography (Smith \& McAllan, I971). It was found that, in addition to lactose, glucose and galactose, small amounts of two other sugars, which were eluted from the column in the same position as arabinose and xylose, were present. The amounts of these sugars increased with 


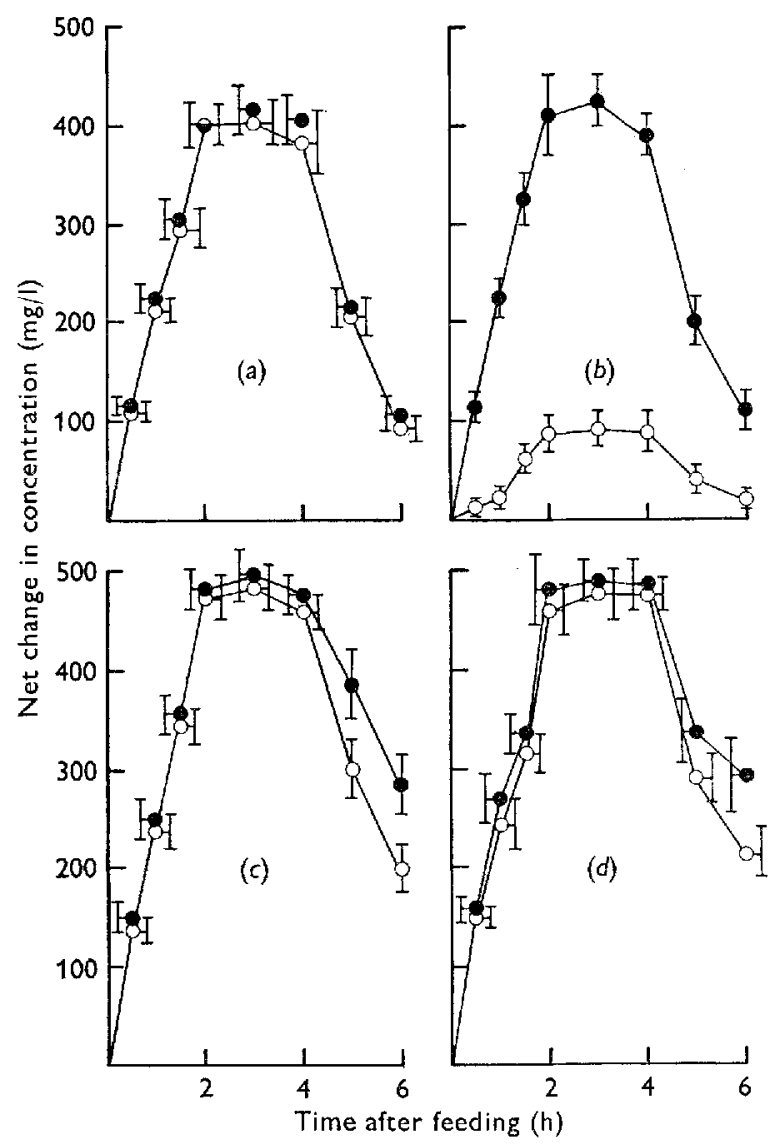

Fig. 5. Change with time in the concentrations of glucose $(O)$ and total reducing sugar (C) in the jugular blood of calves aged 5-32 d given feeds containing (a) $100 \mathrm{~g}$ glucose, $(b)$ I $00 \mathrm{~g}$ galactose, $(c)$ roo g glucose + roo g galactose, and $(d) 200 \mathrm{~g}$ lactose. Each point is the mean (standard error shown by the vertical bar) of results for four calves; results from each calf are themselves mean values obtained from three experiments.

increasing lactose concentration in the infusate; assuming them to be arabinose and xylose, the amounts were approximately 0.06 and $0.07 \mathrm{mmol} / 1$, respectively, per I mmol of lactose infused per 1 . Neither sugar was found to be an impurity of the infused lactose and neither was found in the loop effluent after infusion of a sugarfree solution or solutions containing glucose, galactose, or mixtures of glucose and galactose.

Fig. 4 shows the amounts of sugars, relative to the non-absorbed marker PEG, left in the abomasum and small intestine of calves slaughtered at I week of age after synthetic feeds containing galactose, glucose + galactose or lactose had been given. Galactose absorption took place efficiently in the proximal half of the intestine when only this sugar was present in the feed (Fig. 4 ), but when equal amounts of glucose and galactose were present, glucose was preferentially absorbed in the proximal intestine and galactose absorption was displaced to the more distal part of the intestine (Fig. $4 b$ ). When a lactose-containing diet was used, lactose was rapidly hydrolysed 
in the proximal quarter of the intestine, and thereafter the absorption of the released monosaccharides was similar to that observed after calves had received mixtures of glucose and galactose (Fig. 4c). All these experiments were duplicated, and the patterns of removal of sugars were closely similar. Pairs of calves at 8 weeks of age were given the same group of synthetic diets containing galactose alone, glucose+ galactose, or lactose. Results for galactose alone or for glucose-galactose mixtures were not appreciably different from those for I-week-old calves. However, in the 8-week-old calves given lactose-containing diets, the amount of lactose that remained unhydrolysed in the proximal quarter of the intestine was slightly greater than in $\mathrm{I}$-week-old calves. For example, the amounts of lactose remaining in section $\mathrm{I}$ of the intestines were 13.5 and $15.4 \mathrm{~g} / 1$ in the two I-week-old calves and 20.9 and $19.4 \mathrm{~g} / 1$ in the two 8-week-old calves.

The concentration of any sugar found in the intestinal contents of calves given diets with no added sugar was never greater than $2 \mathrm{~g} / \mathrm{l}$.

\section{Blood sugar responses}

Feeding experiments. The results in Fig. $5 a, b$ show that the ingestion of both glucose and galactose caused a marked increase in the concentrations of total reducing sugar in the blood. After a glucose feed, this increase was due solely to a rise in blood glucose; after a galactose feed, it was mainly due to a rise in the 'non-glucose' reducing sugar. Analysis of sugars by anion-exchange chromatography, in borate-treated blood samples taken from calves that had received galactose diets, showed that glucose and galactose were the only two sugars present. Therefore, the difference between values for total reducing sugar (taking account of the different sensitivities of glucose and galactose) and for glucose in Fig. $5^{b}$ are a true measure of the galactose present.

After any one calf had been given a diet containing $100 \mathrm{~g}$ glucose $+100 \mathrm{~g}$ galactose, the increase in total reducing sugar in the blood was always greater than that which occurred after the ingestion of $100 \mathrm{~g}$ glucose alone by the same calf. This is shown in Fig. $5 a, c$. This increase was not, however, as great as would be expected if the two sugars were absorbed independently, and was due almost entirely to an increase in the concentration of blood glucose.

In calves given $200 \mathrm{~g}$ lactose, the increases in concentrations of blood sugars were very similar to those in calves given glucose-galactose mixtures, and little or no rise in blood galactose was detected (Fig. $5 d$ ).

Duodenal infusion experiment. When a solution of galactose labelled uniformly with ${ }^{14} \mathrm{C}$ was infused into the intestine, the concentration of ${ }^{14} \mathrm{C}$ in the plasma was expressed in terms of a '[14C]galactose equivalent' concentration. This was defined as that amount of galactose which would have been associated with the ${ }^{14} \mathrm{C}$ activity in the plasma if none of the galactose absorbed from the infusate had been metabolized. That such metabolism did occur was indicated by a greater and more rapid increase in the ' $\left[{ }^{14} \mathrm{C}\right]$ galactose equivalent' concentration of the plasma than in the galactose concentration in the plasma (Fig. $6 b$ ). The difference between these two concentrations during the first $3.5 \mathrm{~h}$ after the infusion started could be accounted for by an increase in the concentration of a plasma glucose. After $4-5 \mathrm{~h}$, whereas plasma 


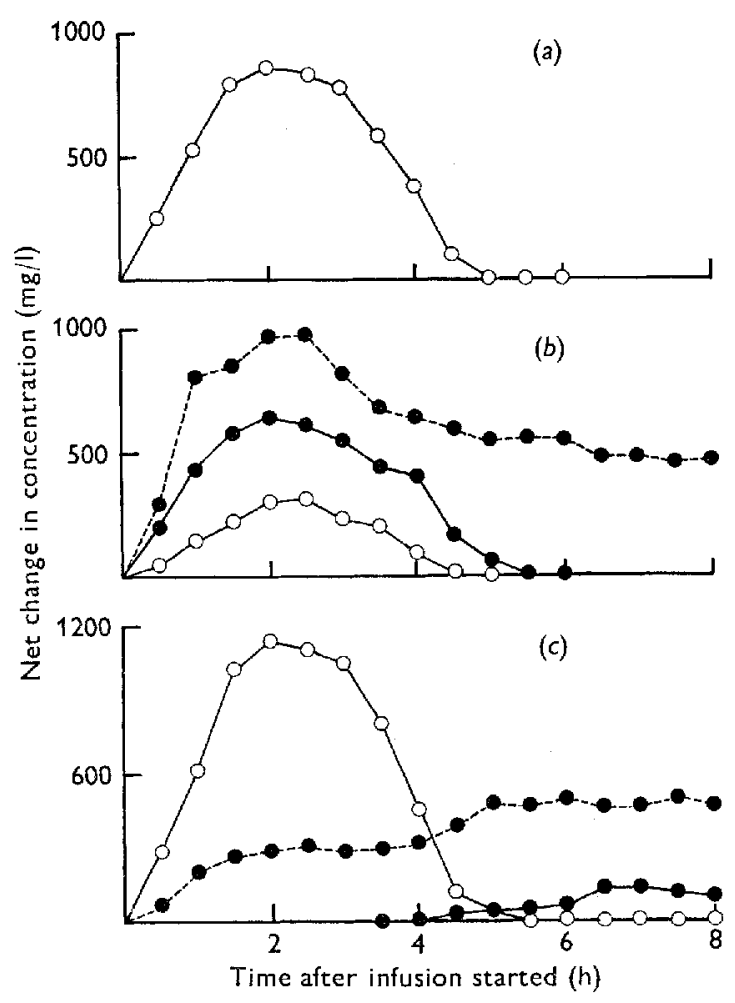

Fig. 6. Change with time in the plasma glucose $(\mathrm{O}-\mathrm{O})$, galactose $(-0)$ and ${ }^{14} \mathrm{C}(--0)$ concentrations in an 8 -week-old calf after infusion into the duodenum of $(a)$ glucose $(7 \circ \mathrm{g} / \mathrm{l})$, (b) galactose $(7 \circ \mathrm{g} / \mathrm{l})$ labelled with $\left[\mathrm{U}-{ }^{14} \mathrm{C}\right]$ galactose, and $(c)$ glucose $(7 \circ \mathrm{g} / 1)+$ galactose (7o g/l) labelled with $\left[\mathrm{U}-{ }^{14} \mathrm{C}\right]$ galactose. ${ }^{14} \mathrm{C}$ concentrations are expressed as ${ }^{~}\left[{ }^{14} \mathrm{C}\right]$ galactose equivalent' concentrations (see p. 339 for definition). Each point represents the mean of results from three experiments with one calf. Coefficients of variation never exceeded $10 \%$ of the mean.

concentrations of glucose and galactose had returned to their pre-infusion levels, the ' $\left.{ }^{14} \mathrm{C}\right]$ galactose equivalent' concentration was maintained at about $500 \mathrm{mg} / 1$ during the final $3 \mathrm{~h}$ of sampling. When a glucose-galactose mixture containing a $\left[{ }^{14} \mathrm{C}\right]$ galactose label was infused, the plasma glucose increased more rapidly and to a greater extent during the first $2 \mathrm{~h}$ than when glucose alone was infused (Fig. 6a, c) and, although no rise in the concentration of plasma galactose could be detected, a small increase in the ' $\left[{ }^{14} \mathrm{C}\right]$ galactose equivalent' concentration occurred. After $4 \mathrm{~h}$, the concentration of plasma glucose had returned to the pre-infusion level and small amounts of galactose were detected in the plasma. The ' $\left[{ }^{14} \mathrm{C}\right]$ galactose equivalent' was maintained, or increased slightly, between 2 and $5 \mathrm{~h}$ and achieved a value of about $500 \mathrm{mg} / \mathrm{l}$.

fugular infusion experiments. The effect on blood sugar concentrations of infusing glucose, galactose and glucose-galactose mixtures into the jugular blood of calf $6 \mathrm{C}$ is shown in Fig. 7. When galactose alone was infused, in addition to an increase in blood galactose there was a small but consistent rise in blood glucose. The increases 


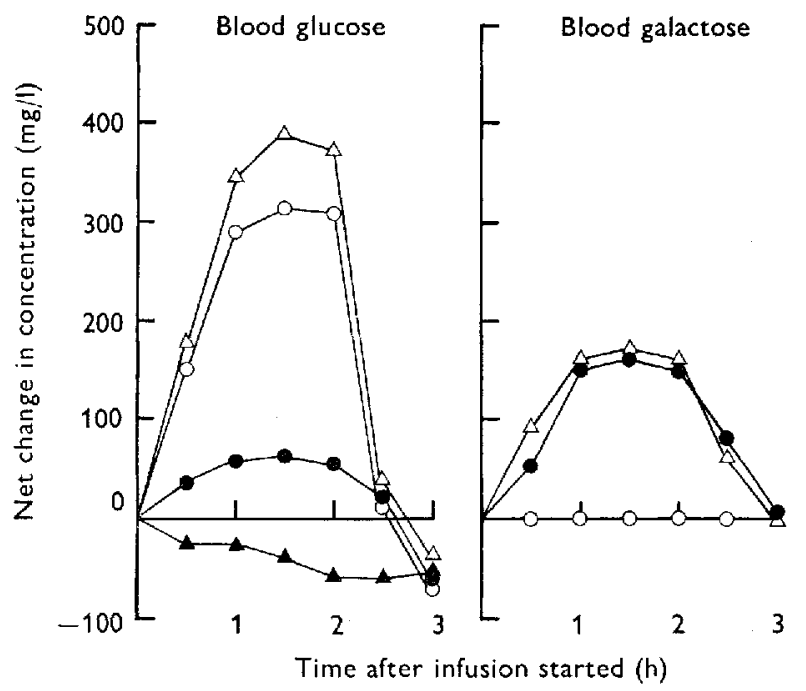

Fig. 7. Change with time in the blood glucose and galactose concentrations of a 4-week-old calf after infusion of a solution of glucose $(28 \mathrm{~g} / 1)(\mathrm{O})$, galactose $(28 \mathrm{~g} / 1)(\mathbf{)})$, glucose + galactose $(28 \mathrm{~g} / 1$ of each sugar) $(\Delta)$ or $\mathrm{NaCl}(9 \mathrm{~g} / \mathrm{l})(\Delta)$ into the jugular vein for $2 \mathrm{~h}$ at $500 \mathrm{ml} / \mathrm{h}$. Results are the means of values from three experiments with calf $6 \mathrm{C}$.

in concentrations of blood sugar that occurred after infusing glucose-galactose mixtures appeared to be the sum of those which resulted from the infusion of glucose and galactose separately.

The other two calves $(7 \mathrm{C}$ and $8 \mathrm{C}$ ) showed similar relationships between the responses to different infusates, although the magnitude of the responses varied considerably between animals. For example, the concentrations of glucose and galactose in samples of blood taken $\mathrm{I} \cdot 5 \mathrm{~h}$ after the infusion of glucose and galactose started were $3^{85}$ and $\mathrm{I} 70,470$ and $2 \mathrm{I} 5$, and $3^{25}$ and $140 \mathrm{mg} / 1$ respectively for calves $6 \mathrm{C}, 7_{7} \mathrm{C}$ and $8 \mathrm{C}$.

\section{DISCUSSION}

Cori (1925) observed that sugars of similar molecular weight were absorbed from the intestine at widely differing rates. This strongly suggested that simple diffusion could not be the sole mechanism of sugar absorption. Since then, the uptake of glucose and galactose against their own concentration gradients has been demonstrated both in vivo (Atkinson, Parsons \& Smyth, 1957) and in vitro (Crane, 1960). Under these conditions of uptake the rate of glucose or galactose absorption did not increase linearly with increasing sugar concentrations in the lumen, suggesting that some rate-limiting step, such as an enzyme system or a carrier molecule, was involved in their absorption. Such non-linear relationships have also been demonstrated in man (Sched1 \& Clifton, I96r; Holdsworth \& Dawson, I964) and in the dog (Annegers, I964) and are also suggested by the responses to feeding with glucose and galactose of the concentrations of sugar in blood from the jugular vein of calves (Siddons $e t$ al. I969). Our results from experiments using intestinal loops in calves (Figs. I $a$ and 3 ) 
are consistent with the view that glucose and galactose are absorbed by a process which involves some rate-limiting factor. Complete saturation of the absorption process, however, was not demonstrated suggesting that simple diffusion may also operate at high concentrations of sugar in the lumen. In these experiments, galactose alone was absorbed at least as rapidly as glucose alone at a wide range of infusate concentrations (Fig. $\mathrm{I} a, b$ ), suggesting that these two sugars possess similar affinities for this ratelimiting factor.

Demonstrations of mutual inhibition of glucose and galactose uptake by in vitro preparations of small intestine (cf. Fisher \& Parsons, r953; Landau \& Wilson, 1959; Crane, I960) have led to the general conclusion that these two sugars share the same transport system. If this were so, one would expect competition to occur between the two sugars when they are present in the gut lumen together, and the degree of inhibition of transport of one sugar by the other would depend on their relative affinities for the transport system and their relative concentrations at the site of absorption. Previous experiments with the calf (Siddons et al. 1969) suggested, however, that mutual inhibiticn between glucose and galactose did not occur; after calves had been fed with glucose-galactose mixtures, no increase in concentration of galactose in jugular blood was detected, although blood glucose increased to a concentration similar to that found after feeding with glucose alone. This observation was confirmed in the present work on blood-sugar responses (Fig. $5^{b}, c$ ). However, the response in sugar concentrations in the jugular blood to feeding with various sugars need not necessarily provide a reliable indication of relative rates of sugar absorption, and therefore the competition for uptake between glucose and galactose has been studied by means of intestinal loops. In these experiments, when equimolar mixtures of glucose and galactose were infused into intestinal loops, whereas galactose absorption was severely depressed by the presence of glucose, glucose absorption was apparently unaffected by the presence of galactose (Fig. Ic). These results are in good agreement with those from in vivo experiments carried out by other workers using different species. For example, Holdsworth \& Dawson (1964) found no inhibition of glucose absorption by galactose in man, whereas galactose absorption was considerably reduced in the presence of glucose. Annegers (1964) made similar observations in dogs although, later (Annegers, I968), he concluded that the inhibitory effect of galactose on glucose absorption was not significantly less than that of glucose on galactose absorption.

It appeared (Fig. $4^{b}$ ) that, when glucose-galactose mixtures were introduced into the whole small intestine, glucose absorption occurred rapidly in the proximal half of the intestine, but galactose absorption was depressed in this region. However, galactose absorption occurred efficiently in the more distal intestine, presumably once the glucose concentration in the digesta had been reduced. Thus in the whole small intestine both sugars were removed with almost equal efficiency. This was confirmed by the results of earlier experiments, in which collections of digesta from the terminal ileum were made after feeding with glucose-galactose mixtures; even when $200 \mathrm{~g}$ of glucose with $200 \mathrm{~g}$ of galactose were given to calves, no more than $3 \mathrm{~g}$ of either sugar appeared in the ileal effluent (unpublished results). 
It is necessary, therefore, to consider why little or no galactose could be detected in the blood after feeding with mixtures of glucose and galactose (Fig. $5 b$ ) or after infusion of such mixtures into the small intestine (Siddons et al. I 669 ). When galactose alone entered the small intestine, or was infused direct into the jugular vein, an increase in blood glucose was always detected as well as the appearance of galactose in the blood. It was clear, therefore, that metabolism of galactose to glucose occurred, presumably in the liver. To determine how much blood glucose originated from galactose when glucose-galactose mixtures were introduced into the intestine, experiments were carried out in which the galactose in such mixtures was labelled with [U-14 C]galactose. The results summarized in Fig. 6 support the view that in the first $3 \mathrm{~h}$ after infusion of galactose + glucose into the small intestine, glucose was absorbed rapidly and galactose absorption was depressed to such an extent that any galactose absorbed was immediately converted into glucose. Once all the glucose had been absorbed, the galactose absorption rate increased until it eventually exceeded the rate at which galactose was converted into glucose. It seems likely that when galactose is administered alone its absorption rate is so rapid that it exceeds its rate of metabolism and a rise in blood galactose occurs, whereas, in the presence of glucose, galactose absorption is depressed to a level at which galactose is metabolized to glucose more rapidly than it is absorbed. The finding that the plasma concentration of ${ }^{14} \mathrm{C}$ appeared to reach a fairly steady state at about $500 \mathrm{mg} / \mathrm{l}$ after about $6 \mathrm{~h}$, whether glucose was present in the infusate or not, suggested that, in both instances, the total amount of galactose absorbed was about the same and that much of the absorbed $\left[{ }^{14} \mathrm{C}\right]$ galactose was eventually metabolized to $\left[{ }^{14} \mathrm{C}\right]$ glucose, which then equilibrated with the glucose normally circulating in the blood of the fasting animal.

Results for slaughtered animals showed that glucose and greater amounts of galactose accumulated in the gut lumen after feeding with lactose, suggesting that the rate of lactose hydrolysis exceeded the rate of monosaccharide absorption. This view was supported by the finding that considerable amounts of glucose and galactose appeared in the effluent after lactose had been infused into intestinal loops and by the finding that glucose and galactose were absorbed as rapidly from lactose as from glucose-galactose mixtures. Thus, lactose hydrolysis to glucose and galactose takes place rapidly, and the free sugars diffuse away from the site of hydrolysis and accumulate in the gut lumen. Once released, they are absorbed in a similar manner to that described above for glucose-galactose mixtures in that both sugars are absorbed efficiently but from different regions of the small intestine.

It appears that this mechanism differs from that in other mammals investigated. For example, Gray \& Santiago (1966) found that, in man, the absorption rates of glucose and galactose from lactose were considerably slower than those from equivalent glucose-galactose mixtures, and, although some intraluminal accumulation of glucose and galactose occurred, they concluded that the hydrolysis stage was rate-limiting in the removal of lactose from the gut.

The slaughter experiments showed that the amounts of lactose remaining in theintestines of the 8-week-old calves were only slightly greater than those in the intestines of the I-week-old calves, despite the fact that Siddons (1968) found approximately 
a fivefold decrease in the specific lactase activity of the calf between these ages. However, the specific lactase activity of the 8-week-old calf is still approximately ten times that of the adult animal and, therefore, although hydrolysis does not appear to be the rate-limiting factor in the removal of lactose from the intestinal lumen of the calf up to 8 weeks of age, it is possible that it may become so in the older animal.

We thank Dr H. L. Buttle and Mr S. C. Watson for carrying out all surgical operations and Mrs S. J. Askew for supervising the care of the animals and for taking most of the blood and digesta samples.

\section{REFERENCES}

Annegers, J. H. (1964). Am. J. Physiol. 206, 1095.

Annegers, J. H. (I968). Proc. Soc. exp. Biol. Med. 127, ro7r.

Ash, R. W. (1962). Anim. Prod. 4, 309.

Atkinson, R. M., Parsons, B. J. \& Smyth, D. H. (1957). F. Physiol., Lond. 135, $5^{8}$ I.

Badawy, A. M., Campbell, R. M., Cuthbertson, D. P., Fell, B. F. \& Mackie, W. S. (1958). Br. F. Nutr. I2, 367 .

Coombe, N. B. \& Smith, R. H. (197I). Proc. Nutr. Soc. 3o, 90A.

Cori, C. F. (1925). F. biol. Chem. 66, 691.

Crane, R. K. (Ig60). Physiol. Rev. 40,789.

Dahlqvist, A. (I96I). Biochem. F. 80, 547.

Fisher, R. B. \& Parsons, D. S. (1953). F. Physiol., Lond. r19, 224.

Gray, C. M. \& Santiago, N. A. (1966). Gastroenterology 5I, 489 .

Holdsworth, C. D. \& Dawson, A. M. (I964). Clin. Sci. 27, 37 I.

Hydén, S. (1955). K. LantbrHögsk. Annlr 22, т 39 .

Landau, B. R. \& Wilson, T. H. (I959). F. biol. Chem. 234, 749.

Roth, H., Segal, S. \& Bertoli, D. (1965). Analyt. Biochem. 10, 32.

Roy, J. H. B., Shillam, K. W. G., Hawkins, G. M. \& Lang, J. M. (1958). Br. F. Nutr. 12, I23.

Schedl, H. P. \& Clifton, J. A. (1961). F. clin. Invest. 40, 1079.

Siddons, R. C. (1968). Biochem. $\mathcal{F}$. ro8, 839.

Siddons, R. C., Smith, R. H., Henschel, M. J., Hill, W. B. \& Porter, J. W. G. (1969). Br. F. Nutr. 23, 333 .

Smith, R. H. (1958), Nature, Lond. I82, 260.

Smith, R. H. \& McAllan, A. B. (1971). Automation in Analytical Chemistry (Technicon International Symposium, 1969) p. 207. Basingstoke, Hants.: Technicon Instruments Company Ltd.

Velu, J. C., Kendall, K. A. \& Gardner, K. E. (1960). F. Dairy Sci. 43, 546. 